\title{
Benefits of multidisciplinary teamwork in the management of breast cancer
}

This article was published in the following Dove Press journal:

Breast Cancer:Targets and Therapy

29 August 2013

Number of times this article has been viewed

\section{Cath Taylor' \\ Amanda Shewbridge ${ }^{2}$ \\ Jenny Harris' \\ James S Green ${ }^{3,4}$}

'Florence Nightingale School of Nursing and Midwifery, King's College London, London UK; ' ${ }^{2}$ Breast Cancer Services, Guy's and St Thomas' NHS Foundation Trust, London, UK; ${ }^{3}$ Department of Urology, Barts Health NHS Trust, London, UK; ${ }^{4}$ Department of Health and Social Care, London South Bank University, London, UK
Correspondence: Cath Taylor Florence Nightingale School of Nursing and Midwifery, Room 3.2I, James Clerk Maxwell Building, King's College London, London SEI 8WA, UK

Tel +442078483508

Fax +44 2078363764

Email cath.taylor@kcl.ac.uk
Abstract: The widespread introduction of multidisciplinary team (MDT)-work for breast cancer management has in part evolved due to the increasing complexity of diagnostic and treatment decision-making. An MDT approach aims to bring together the range of specialists required to discuss and agree treatment recommendations and ongoing management for individual patients. MDTs are resource-intensive yet we lack strong (randomized controlled trial) evidence of their effectiveness. Clinical consensus is generally favorable on the benefits of effective specialist MDT-work. Many studies have shown the benefits of receiving treatment from a specialist center, and evidence continues to accrue from comparative studies of clinical benefits of an MDT approach, including improved survival. Patients' views of the MDT model of decision-making (and in particular its impact on involvement in decisions about their care) have been under-researched. Barriers to effective teamwork and poor decision-making include excessive caseload, low attendance at meetings, lack of leadership, poor communication, role ambiguity, and failure to consider patients' holistic needs. Breast cancer nurses have a key role in relation to assessing holistic needs, and their specialist contribution has also been associated with improved patient experience and quality of life. This paper examines the evidence for the benefits of MDT-work, in particular for breast cancer. Evidence is considered within a context of growing cancer incidence at a time of increased financial restraint, and it may now be important to reevaluate the structure and models of MDT-work to ensure that MDTs are an efficient use of resources.

Keywords: interdisciplinary teams, interprofessional interactions, multidisciplinary collaboration, teams, teamwork

\section{Introduction}

There have been significant advances in the diagnosis and treatment of breast cancer over the past 20 years, due to increased knowledge about the biology and molecular changes in breast cancer. Comprehensive profiling at the molecular level has led to understanding of breast cancer not as a single disease but heterogeneous, ${ }^{1}$ and facilitated the development of personalized medicine (eg, targeted therapies such as trastuzumab for HER2-positive cancers) that are far more sophisticated than previously available treatment. These advances have increased the complexity of treatment decision-making for individual women, and reinforced the need for a team approach to treatment decision-making.

Multidisciplinary teams (MDTs), consisting of medical, nursing, allied professionals, and diagnostic experts, have arguably "naturally" evolved alongside advances in treatment, due to the requirement for a range of specialist expertise in order to 
determine the optimal treatment pathway for individual patients. MDTs are now firmly established at the core of cancer care in many countries worldwide. This article aims to synthesize evidence of the benefits of MDT-work, in particular for breast cancer.

\section{Defining multidisciplinary care}

Multidisciplinary cancer care is described using various terms: MDTs, multidisciplinary case/cancer conferences, and tumor boards are all forms of multidisciplinary cancer care. The core elements are inclusion of a range of health professionals who can make unique contributions to decisionmaking about the management of individual patients, and a forum in which they can communicate these contributions. A multidisciplinary team is defined by the UK Department of Health as "a group of people of different health care disciplines which meets together at a given time (whether physically in one place or by video or teleconferencing) to discuss a given patient and who are each able to contribute independently to the diagnostic and treatment decisions about the patient." ${ }^{2}$

Whilst the increasing complexity of treatment decisions provides a strong rationale for MDT-work, its existence is not universal. A global survey, completed by principal investigators from 39 countries participating in a phase III trial, showed that mandatory MDT-work for breast cancer ranged from approximately two-thirds of centers in Eastern/Western Europe to only a quarter of centers in South America and a third in Asia. ${ }^{3}$ Even within centers that reported having mandatory MDT care, most lacked national or regional guidelines regarding composition or practice of MDT-work to ensure consistency of provision (only 19\% reported having such guidelines). The variation in format and function of MDTs has previously been reported in relation to tumor boards in the US. ${ }^{4}$ Furthermore, tumor boards are often solely "medically" focused: a recent survey of 138 providers within one health system in the US found less than a third listed having social workers, nutritionists, or palliative care specialists as members (nurses were not even mentioned). ${ }^{5}$

In the UK, MDTs are a mandatory component of cancer care and are regulated through a "peer review" program that assesses adherence to national tumor-specific guidance regarding their structure and processes. ${ }^{2,6}$ The guidance includes specifying the membership in relation to professional group and degree of specialism, separating into "core" (mandatory) and "extended" (recommended) members. For breast cancer, core membership includes two designated breast surgeons, a clinical oncologist (radiation oncologist), a medical oncologist (where the responsibility for chemotherapy is not undertaken by the clinical oncology core member), two imaging specialists, two histopathologists, two breast cancer nurse specialists, and an MDT coordinator/ secretary. Extended team members include a reconstructive/ plastic surgeon, physiotherapist/lymphedema specialist, psychiatrist or clinical psychologist, and a social worker.

\section{What difference does it make? Reviewing the evidence of benefit}

MDTs have been established as a cornerstone of cancer care in the UK and other countries worldwide prior to robust demonstration of effectiveness. ${ }^{7,8}$ The value of an MDT approach to decision-making and management has been tested subsequent to implementation of MDTs. In many countries, national policy supporting an MDT approach prevents a "gold standard" randomized controlled trial evaluation of the effectiveness of MDT care, and may raise ethical dilemmas as well as methodological complexities, even where policy does not exist. Evidence of benefit therefore arises from weaker (quasi-experimental) study designs such as "before/after" or comparative studies, which require cautious interpretation due to risk of bias caused by "time" (improved outcomes due to other changes over time, such as better treatments) or other potential confounders of outcomes.

\section{Clinical benefit}

A systematic review conducted in $2010^{9}$ found that twelve studies reported a significant relationship between MDT care and survival (including four on breast cancer), but concluded that the pooling of data to provide more definitive evidence was prevented by methodological limitations. These included poor definitions of the MDT interventions and/or heterogeneous MDT models, the fact that temporal changes may confound findings in before-and-after studies, and that data may not be sufficiently accurate or comprehensive when drawn from cancer registry databases.

An opportunity for evaluating the relationship with survival in a contemporaneous comparative design (thereby overcoming temporal bias) was provided by the introduction of MDT-work in one but not other health boards in a region of Scotland. ${ }^{10}$ Data from over 13,000 women diagnosed with symptomatic invasive breast cancer between 1990 and 2000 were included. Adjusting for case mix (including year of incidence, age at diagnosis, and deprivation), the researchers found that prior to the introduction of MDTs, breast cancer mortality was $11 \%$ 
higher in the intervention area compared with other areas in the region, but after MDTs were introduced, mortality was $18 \%$ lower than the other areas. They used an interrupted time-series approach to adjust for trends in survival before the intervention was introduced, and found that the improvement in survival in the intervention area was significantly greater than the predicted levels based on the trends.

A similar opportunity for contemporaneous comparison was taken in Sweden where breast cancer-survival rates were compared across seven counties in one region. ${ }^{11}$ Seven-year relative survival in one county was significantly worse than in the others. The main explanatory factor for this difference was a lower rate of diagnostic activity, and once the region had established MDTs and adhered to the regional guidelines, the diagnostic activity levels rose and differences in survival across the regions were eliminated. Similar findings have been reported in studies of other tumor types, most recently for upper gastrointestinal cancer in Norway, ${ }^{12}$ though the presence/absence of MDT intervention was measured in terms of being theoretically possible according to the availability of a range of specialists in each county. The longitudinal design allowed examination of change in MDT status. Survival in counties with MDT availability was significantly greater than in counties without, probably at least in part accounted for by their increased use of chemotherapy.

The importance of being treated by specialists is well established. ${ }^{13,14}$ This includes evidence of benefit where surgeons operate on at least 30 breast cancers per year ${ }^{15}$ and treatment benefits from multiprofessional specialist input, such as increased use of adjuvant and hormone therapy, fewer mastectomies, and higher rates of breast-conserving surgery. These findings are particularly evident in studies that have compared outcomes (including survival) for patients treated in large regional centers (eg, teaching hospitals) with smaller secondary-care hospitals. ${ }^{14,16-22}$ Similar findings have been reported in studies of other tumor types. ${ }^{23-25} \mathrm{~A}$ study involving 72 breast cancer teams in the $\mathrm{UK}^{26}$ found that higher caseload (per whole-time equivalent team member) was an important indicator of clinical performance, as was having a higher proportion of breast cancer nurses (BCNs).

\section{Breast cancer nurses}

The BCN role first emerged in the 1970s, when the need to identify and address psychosocial concerns in women diagnosed with breast cancer was first noted. ${ }^{27,28}$ Since that time, the role of the $\mathrm{BCN}$ has continually evolved, and in the UK it is mandatory for MDTs to have a $\mathrm{BCN}$ as a core member of the MDT. The importance of the BCN to patient experience and quality of life has been demonstrated. ${ }^{29,30}$ They are often the patient's key worker (named point of contact), and thereby the only consistent point of reference through the care pathway. ${ }^{31}$ Key elements of their role include providing information, psychological support, advocacy, and coordinating care through the pathway. ${ }^{32,33}$ They have a central role in ensuring holistic assessment of patients' needs (including physical, psychological, social, spiritual, sexual, and cultural issues). ${ }^{34}$ Earlier diagnosis and better treatments have led to an increasing population of women surviving breast cancer and coping with the impacts of the cancer or treatments on their lives. ${ }^{35,36}$ BCNs have an important role in identifying such needs and concerns and signposting patients to appropriate services. Nurse-led interventions have included providing tailored information to inform patient decision-making, ${ }^{37}$ leading changes to follow-up services, ${ }^{38}$ and developing endof-treatment clinics. ${ }^{39}$ Emerging evidence from small-scale studies suggests that nurses may have limited participation in MDT meetings. ${ }^{40}$ This may be due to longstanding hierarchies that value contributions from medical and diagnostic perspectives above nursing perspectives. ${ }^{41}$ Given that a key component of the nurse's role is that of patient advocate and/or key worker, it is essential to address any such barriers and ensure nurses have an equal voice in MDT discussions.

\section{Health-professional views}

Clinical opinion regarding the value of MDTs has been predominantly positive. A survey of over 2,000 cancer health professionals in the UK, ${ }^{42}$ repeated in an international study of breast cancer professionals ${ }^{3}$ showed that over $90 \%$ of respondents agreed that effective MDT care results in improved clinical decision-making, better coordinated patient care, more evidence-based treatment decisions, and improved overall quality of treatment. Some authors have been more critical about the value of MDTs,${ }^{43}$ in part based on the methodological limitations of the evidence, but also acknowledging the cost of MDTs and potential barriers to effective teamwork. MDTs are very resource-intensive, though estimates of costs varied significantly in a recent exercise by the UK National Cancer Action Team (submitted costs from trusts across the UK ranged from $£ 14$ to $£ 643$ per treatment plan). ${ }^{44} \mathrm{~A}$ recent systematic review concluded that current evidence was insufficient to draw any conclusions regarding the cost-effectiveness of MDT care. ${ }^{45}$ The increasing financial restraints on health care in many countries worldwide coupled with the increased cancer incidence (and 
thereby MDT workload) supports a greater focus on ensuring that MDTs are an efficient use of resources.

\section{Patients' experiences and views about MDT-work}

Little is known about the impact of MDT-work on patients' experience of their care, or their views on having their treatment coordinated and agreed on by a team, some of whom they may know and meet face-to-face, while others will remain largely anonymous to them. It has been suggested that this raises issues of confidentiality and data protection, ${ }^{43}$ though we lack knowledge of patients' views about this. Treatment-discussion meetings do not generally involve the patient, nor is this deemed desirable or practical by health professionals, according to a UK survey. ${ }^{42}$ Each patient case discussion is estimated to last 4-6 minutes ${ }^{46,47}$ and requires team members to feel able to debate and have frank discussions in the best interests of the patient, underpinned by consideration of complex radiological and histopathological data. Much would need to be changed to support patients to attend MDT meetings, including consideration of the likely impact it would have on the length of meetings. Patient participation in breast cancer MDT meetings has been piloted in Australia, where it was reported to be acceptable to both staff and patients. ${ }^{48}$ Enhancing shared decision-making is at the heart of current reforms in the UK National Health Service (NHS), using the slogan "No decision about me without me." ${ }^{99,50}$ Whilst there has been a wealth of research regarding doctor-patient communication and involvement in decision-making at an individual doctor-patient level, there has been very little focus on how best to ensure active patient involvement in decisions about treatment in the context of MDT decision-making forums.

\section{Technological advances and the MDT}

Tele/videoconferencing is fast becoming a norm of MDTwork in the UK and elsewhere to facilitate collaborative decision-making. Compared to face-to-face meetings, it has been shown to lead to comparable decisions in terms of quality, ${ }^{50-52}$ and has obvious advantages in relation to time, convenience, and cost. This clearly depends on having sufficient investment in standardized equipment to enable high-quality conversations and sharing of imaging. ${ }^{53,54}$ MDTs are a hugely expensive resource, due to the requirement to have many experts available at the same time. In recent years, the potential for virtual teams in health care has been discussed to overcome the barriers that time and geography present. ${ }^{55,56}$ There are increasing numbers of Information Technology companies interested in developing patient-pathway tracking software and real-time MDT meeting software (some of which operate as decision-making aids, eg, http://mate.cossac.org). ${ }^{57}$ Such software solutions - if effective and acceptable to the end users - may also have other benefits, such as helping teams to focus on complex (non-routine) cases for discussion and also to identify potentially eligible patients for recruitment to trials. Although discussion of patients in MDT meetings has been associated with improved recruitment to trials, ${ }^{58}$ research regarding MDT members' informational roles has shown a lack of clarity regarding the responsibility for discussing trials with patients, which may lead to missed recruitment opportunities. ${ }^{59-61}$ Software solutions that alert the team to potentially eligible patients for trials may support more systematic MDT discussion and action planning with specified team member responsibilities.

\section{Barriers to effective MDT-work}

There are many ingredients required for effective teamwork in MDTs. A report published by the UK National Cancer Action Team in $2010^{62}$ (based on clinical consensus in over 2,000 MDT members) described over 100 recommendations for effective MDT-work. These recommendations are organized under five domains: the team, infrastructure for meetings, meeting organization and logistics, patient-centered clinical decision-making, and team governance. Similar frameworks have been used to describe effective MDT-work elsewhere, eg, in Australia. ${ }^{63}$ Audit and research evidence from the UK and other countries shows that MDTs vary in relation to these domains and that there are many obstacles to effective MDT-work. ${ }^{40,64}$

A systematic review ${ }^{40}$ highlighted time pressure, excessive caseload, low attendance at MDT meetings, poor teamwork and lack of leadership as features related to poor-quality decision-making in MDTs. Poor communication within the team and role ambiguity (eg, poor definition/understanding of roles within the team) can lead to dysfunctional teamwork. ${ }^{8,59}$ Communication with colleagues has been cited as a major source of stress in MDTs, ${ }^{65,66}$ though providing care in MDTs is generally reported to be an important source of job satisfaction, ${ }^{42,46}$ and $90 \%$ of over 2,000 UK cancer health professionals reported MDT-work as beneficial to mental health. ${ }^{42}$

One particular focus of several studies has been the quality of decision-making in MDT meetings. Several studies have examined the concordance of final treatment plans with MDT recommendations in a range of tumor types. ${ }^{67-70}$ Actual treatment was discordant in up to $15 \%$ of cases. Predominant reasons were lack of consideration of holistic information 
about the patient, including comorbidities and their preferences for treatment. This could be caused by a range of issues, including not collecting such information from patients prior to MDT discussion, having insufficient time for preparation and/or inadequate presentation in meetings, or lack of inclusiveness of MDT discussions, particularly in relation to nurses' contributions. ${ }^{41,71}$

\section{MDT development}

There is a need to identify the active ingredients (or mechanisms) by which MDT-work confers benefit in relation to clinical outcomes, patient experience, and staff well-being and experience. From this, MDT care can be better defined and standardized to provide optimal care to all patients with breast cancer. The increasing prevalence of cancer coupled with workforce shortages and other time pressures make it ever more important that time spent in MDT meetings is used efficiently. Ensuring good preparation (collating all relevant tumor and patient-based information prior to meetings) will enable better organization of case discussions, allowing routine protocol-led cases to be discussed and agreed upon quickly and allowing more time for complex cases. Recognition of the current barriers to effective MDT-work and implementing strategies to reduce or remove their impact is also important. Various tools have been developed and tested in the UK to assess the quality of teamwork in cancer teams. These include both independent observational tools to assess teamwork in MDT meetings ${ }^{72,73}$ and a team selfassessment tool that facilitates anonymized team-member self-assessment of teamwork across the whole pathway (not just focusing on MDT meetings). ${ }^{74}$ This latter tool is a component of an evidence-based team-improvement intervention called MDT-FIT (Feedback for Improving Teamworking), developed on behalf of the UK National Cancer Action Team. Based upon input and testing with over 100 MDTs, it is an assessment-and-feedback process that provides teams with the space to reflect on how they are working as a team and prioritize actions for improvement. Currently in a final stage of evaluation with ten breast cancer teams within a large cancer network, teams typically identify six to eight areas for improvement, and the majority are implemented within 6-9 months. ${ }^{75}$

\section{Conclusion}

A specialist team approach to breast cancer management may lack randomized controlled trial evidence of effectiveness, but is considered superior based upon both clinical consensus and research evidence. In most health care systems, there is pressure to "do more with less": be more efficient, but with fewer resources. MDT-work appears to raise the quality of care, but as the teams were often implemented at pace (and 10-20 years ago), it may now be important to reevaluate the structure and models of MDT-work to determine how the best teams work, what comprises the best team nucleus and leadership styles, the best methods to allow shared learning, self-assessment, and feedback, and the most appropriate outcomes to enable more accurate evaluation of MDT care. This will allow teams to be the very best they can with the resources available.

\section{Disclosure}

The authors report no conflicts of interest in relation to this manuscript.

\section{References}

1. Polyak K. Breast cancer origins and evolution. J Clin Invest. 2007;117(11):3155-3163.

2. Department of Health. Manual for Cancer Services. London: Department of Health; 2004.

3. Saini KS, Taylor C, Ramirez AJ, et al. Role of the multidisciplinary team in breast cancer management: results from a large international survey involving 39 countries. Ann Oncol. 2012;23(4):853-859.

4. Henson DE, Frelick RW, Ford LG, et al. Results of a national survey of characteristics of hospital tumor conferences. Surg Gynecol Obstet. 1990;170(1):1-6.

5. Keating NL, Landrum MB, Lamont EB, Bozeman SR, Shulman LN, McNeil BJ. Tumor boards and the quality of cancer care. J Natl Cancer Inst. 2013;105(2):113-121.

6. National Institute for Clinical Excellence. Improving Outcomes in Breast Cancer. London: NICE; 2002.

7. Taylor C, Munro AJ, Glynne-Jones R, et al. Multidisciplinary team working in cancer: what is the evidence? BMJ. 2010;340:c951.

8. Fleissig A, Jenkins V, Catt S, Fallowfield L. Multidisciplinary teams in cancer care: are they effective in the UK? Lancet Oncol. 2006;7(11) 935-943.

9. Hong NJ, Wright FC, Gagliardi AR, Paszat LF. Examining the potential relationship between multidisciplinary cancer care and patient survival: an international literature review. J Surg Oncol. 2010;102(2): 125-134.

10. Kesson EM, Allardice GM, George WD, Burns HJG, Morrison DS. Effects of multidisciplinary team working on breast cancer survival: retrospective, comparative, interventional cohort study of 13,722 women. BMJ. 2012;344:e2718.

11. Eaker S, Dickman PW, Hellström V, Zack MM, Ahlgren J, Holmberg L. Regional differences in breast cancer survival despite common guidelines. Cancer Epideimol Biomarkers Prev. 2005;14(12): 2914-2918.

12. Kersten C, Cvancarova M, Mjåland S, Mjåland O. Does in house availability of multidisciplinary teams increase survival in upper gastrointestinal cancer? World J Gastrointest Oncol. 2013;5(3): 60-67.

13. Houssami N, Sainsbury R. Breast cancer: multidisciplinary care and clinical outcomes. Eur J Cancer. 2006;42(15):2480-2491.

14. Selby P, Gillis C, Haward R. Benefits from specialised cancer care. Lancet. 1996;348(9023):313-318.

15. Satariano ER, Swanson MG, Moll PP. Nonclinical factors associated with surgery received for treatment of early-stage breast cancer. $\mathrm{Am} \mathrm{J}$ Public Health. 1992;82(2):195-198. 
16. Kingsmore D, Hole D, Gillis C. Why does specialist treatment of breast cancer improve survival? The role of surgical management. Br J Cancer. 2004;90(10):1920-1925.

17. Lee-Feldstein A, Anton-Culver H, Feldstein PJ. Treatment differences and other prognostic factors related to breast cancer survival. Delivery systems and medical outcomes. JAMA. 1994;271(15):1163-1168.

18. Hand R, Sener S, Imperato J, Chmiel JS, Sylvester JA, Fremgen A. Hospital variables associated with quality of care for breast cancer patients. JAMA. 1991;266(24):3429-3432.

19. Yarnold JR, Bliss JM, Brunt M, et al. Management of breast cancer. Refer women to multidisciplinary clinics. BMJ. 1994;308(6930):168-171.

20. Sainsbury R. Organization of breast cancer services. Cancer Treat Rev. 1997;23 Suppl 1:S3-S11.

21. Schipper H, Dick J. Herodotus and the multidisciplinary clinic. Lancet. 1995;346(8986):1312-1313.

22. Durant JR. How to organize a multidisciplinary clinic for the management of breast cancer. Surg Clin North Am. 1990;70(4):977-983.

23. Burton S, Brown G, Daniels IR, Norman AR, Mason B, Cunningham D. MRI directed multidisciplinary team preoperative treatment strategy: the way to eliminate positive circumferential margins? $\mathrm{Br} J$ Cancer. 2006;94(3):351-357.

24. Davies AR, Deans DA, Penman I, et al. The multidisciplinary team meeting improves staging accuracy and treatment selection for gastroesophageal cancer. Dis Esophagus. 2006;19(6):496-503.

25. Coory M, Gkolia P, Yang IA, Bowman RV, Fong KM. Systematic review of multidisciplinary teams in the management of lung cancer. Lung Cancer. 2008;60(1):14-21.

26. Haward R, Amir Z, Borrill C, et al. Breast cancer teams: the impact of constitution, new cancer workload, and methods of operation on their effectiveness. Br J Cancer. 2003;89(1):15-22.

27. Maguire GP, Lee EG, Bevington DJ, Küchemann CS, Crabtree RJ, Cornell CE. Psychiatric problems in the first year after mastectomy. Br Med J. 1978;1(6118):963-965.

28. Maguire P, Brooke M, Tait A, Thomas C, Sellwood R. The effects of counselling on physical disability and social recovery after mastectomy. Clin Oncol. 1983;9(4):319-324.

29. Redman S, Turner J, Davis C. Improving supportive care for women with breast cancer in Australia: the challenge of modifying health systems. Psychooncology. 2003;12(6):521-531.

30. Halkett G, Arbon P, Scutter S, Borg M. The role of the breast care nurse during treatment for early breast cancer: the patient's perspective. Contemp Nurse. 2006;23(1):46-57.

31. Lafferty J, Rankin F, Duffy C, et al. Continuity of care for women with breast cancer: a survey of the views and experiences of patients, carers and health care professionals. Eur J Oncol Nurs. 2011;15(5): 419-427.

32. Beaver K, Twomey M, Witham G, Foy S, Luker KA. Meeting the information needs of women with breast cancer: piloting a nurse-led intervention. Eur J Oncol Nurs. 2006;10(5):378-390.

33. Amir Z, Scully J, Borrill C. The professional role of the breast care nurse in multidisciplinary breast care teams. Eur J Oncol Nurs. 2004;8(4): 306-314.

34. Richardson A, Tebbit P, Brown V, Sitzia J. Holistic Common Assessment of Supportive and Palliative Care Needs for Adults with Cancer: Assessment Guidance. London: Cancer Action Team; 2007.

35. Richardson A, Addington-Hall J, Amir Z, et al. Knowledge, ignorance and priorities for research in key areas of cancer survivorship: findings from a scoping review. Br J Cancer. 2011;105 Suppl 1:S82-S94.

36. Armes J, Crowe M, Colbourne, L, et al. Patients' supportive care needs beyond the end of cancer treatment: a prospective, longitudinal survey. J Clin Oncol. 2009;27(36):6172-6179.

37. National Cancer Action Team. Personalised Information: Cancer Information Prescriptions. Our Progress So Far. NCAT: London; 2011.

38. Beaver K, Tysver-Robinson D, Campbell M, et al. Comparing hospital and telephone follow-up after treatment for breast cancer: randomised equivalence trial. BMJ. 2009;338:a3147.
39. Armes J, Finnegan-John J, Moore J, Bloomfield J, Shewbridge A, Ream E. End of treatment consultation evaluation [abstract]. Eur $J$ Cancer. 2011;47:S318.

40. Lamb BW, Brown KF, Nagpal K, Vincent C, Green JS, Sevdalis N. Quality of care management decisions by multidisciplinary teams: a systematic review. Ann Surg Oncol. 2011;18(8):2116-2125.

41. Lanceley A, Savage J, Menon U, Jacobs I. Influences on multidisciplinary team decision-making. Int J Gynecol Cancer. 2008;18(2):215-222.

42. Taylor C, Ramirez AJ. Multidisciplinary Team Members'Views about MDT Working: Results from a Survey Commissioned by the National Cancer Action Team. London: National Cancer Action Team; 2009.

43. Thornton S, Dodwell D. Multidisciplinary team working: the emperor without clothes? Br J Hosp Med (Lond). 2012;73(4):186-187.

44. Simcock R, Heaford A. Costs of MDT are small in relation to benefits [letter]. BMJ. 2012;344:e2718.

45. Ke KM, Blazeby JM, Strong S, Carroll FE, Ness AR, Hollingworth W. Are multidisciplinary teams in secondary care cost-effective? A systematic review of the literature. Cost Eff Resour Alloc. 2013;11(1):7.

46. Taylor C, Sippitt J, Collins G, et al. A pre-post test evaluation of the impact of the PELICAN MDT-TME Development Programme on the working lives of colorectal team members. BMC Health Serv Res. 2010;10:187.

47. Fosker C, Dodwell D. The cost of the MDT. BMJ. 2010;340:c951.

48. Choy ET, Chiu A, Butow P, Young J, Spillane A. A pilot study to evaluate the impact of involving breast cancer patients in the multidisciplinary discussion of their disease and treatment plan. Breast. 2007;16(2): 178-189.

49. Department of Health. Equity and Excellence: Liberating the NHS. London: Department of Health; 2010.

50. Coulter A, Collins A. Making Shared Decision-Making a Reality: No Decision about Me Without Me. London: The King's Fund; 2011.

51. Kunkler IH, Prescott RJ, Lee RJ, et al. TELEMAM: a cluster randomised trial to assess the use of telemedicine in multi-disciplinary breast cancer decision making. Eur J Cancer. 2007;43(17):2506-2514.

52. Kunkler IH, Fielding RG, Macnab M, et al. Group dynamics within telemedicine-delivered and standard multidisciplinary team meetings: results from the TELEMAM randomised trial. $J$ Telemed Telecare. 2006;12 Suppl 3:s55-s58.

53. Liddell A, Adshead S, Burgess E. Technology in the NHS: Transforming the Patient's Experience of Care. London: The King's Fund; 2008.

54. Paul DL, Pearlson KE, McDaniel RR. Assessing technological barriers to telemedicine: technology-management implications. IEEE Trans Eng Manage. 1999;46(3):279-288.

55. Demeris G. The diffusion of virtual communities in healthcare: concepts and challenges. Patient Educ Couns. 2006;62(2):178-188.

56. Rothschild SK, Lapidos S, Minnick A, Fogg L, Catrambone C. Using virtual teams to improve the care of chronically ill patients. $J$ Clin Outcomes Manage. 2004;11(6):346-350.

57. Patkar V, Acosta D, Fox J, Jones A, Davidson T, Keshtgar M. A novel support tool for Breast Multidisciplinary Meetings: an advanced evidence based computer decision support technology. Eur J Cancer. 2010;8(3):211.

58. McNair AG, Choh CT, Metcalfe C, et al. Maximising recruitment into randomised controlled trials: the role of multidisciplinary cancer teams. Eur J Cancer. 2008;44(17):2623-2626.

59. Jenkins VA, Fallowfield LJ, Poole K. Are members of multidisciplinary teams in breast cancer aware of each other's informational roles? Qual Health Care. 2001;10(2):70-75.

60. Catt S, Fallowfield L, Jenkins V, Langridge C, Cox A. The informational roles and psychological health of members of 10 oncology multidisciplinary teams in the UK. Br J Cancer. 2005;93(10):1092-1097.

61. Cox A, Jenkins V, Catt S, Langridge C, Fallowfield L. Information needs and experiences: an audit of UK cancer patients. Eur J Oncol Nurs. 2006;10(4):263-272.

62. National Cancer Action Team. The Characteristics of an Effective MDT. London: NCAT; 2010. 
63. National Breast and Ovarian Cancer Centre. Multidisciplinary Meetings for Cancer Care: A Guide for Health Service Providers. Canberra: Department of Health and Ageing; 2005.

64. National Cancer Action Team. National Cancer Peer Review Programme Report 2009/2010: An Overview of the Findings from the 2009/2010 National Cancer Peer Review of Cancer Services in England. London: NCAT; 2010.

65. Fallowfield L, Saul J, Gilligan B. Teaching senior nurses how to teach communication skills in oncology. Cancer Nurs. 2001;24(3):185-191.

66. Fallowfield L, Lipkin M, Hall A. Teaching senior oncologists communication skills: results from phase I of a comprehensive longitudinal program in the United Kingdom. J Clin Oncol. 1998;16(5): 1961-1968.

67. Leo F, Venissac N, Poudenx M, Otto J, Mouroux J. Multidisciplinary management of lung cancer: how to test its efficacy? J Thorac Oncol. 2007;2(1):69-72.

68. Stalfors J, Lundberg C, Westin T. Quality assessment of a multidisciplinary tumour meeting for patients with head and neck cancer. Acta Otolaryngol. 2007;127(1):82-87.

69. Blazeby JM, Wilson L, Metcalfe C, Nicklin J, English R, Donovan JL. Analysis of clinical decision-making in multi-disciplinary cancer teams. Ann Oncol. 2006;17(3):457-460.
70. Wood JJ, Metcalfe C, Paes A, et al. An evaluation of treatment decisions at a colorectal cancer multidisciplinary team. Colorectal Dis. 2008;10(8):769-772.

71. Kidger J, Murdoch J, Donovan JL, Blazeby JM. Clinical decisionmaking in a multidisciplinary gynaecological cancer team: a qualitative study. BJOG. 2009;116(4):511-517.

72. Lamb BW, Wong HW, Vincent C, Green JS, Sevdalis N. Teamwork and team performance in multidisciplinary cancer teams: development and evaluation of an observational assessment tool. BMJ Qual Saf. 2011;20(10):849-856.

73. Taylor C, Atkins L, Richardson A, Tarrant R, Ramirez AJ. Measuring the quality of MDT working: an observational approach. BMC Cancer. 2012;12:202.

74. Taylor C, Brown K, Lamb B, Harris J, Sevdalis N, Green JS. Developing and testing TEAM (Team Evaluation and Assessment Measure) a tool for team self-assessment of cancer MDT performance. Ann Surg Oncol. 2012;19(13):4019-4027.

75. Taylor C, Brown KB, Sevdalis N, Green JSA. Developing and testing a novel, evidence-based and user-tested toolkit for assessing and improving teamworking in multidisciplinary cancer teams. Presented at: the European Cancer Congress; September 24-27, 2011; Stockholm, Sweden.
Breast Cancer: Targets and Therapy

\section{Publish your work in this journal}

Breast Cancer: Targets and Therapy is an international, peerreviewed open access journal focusing on breast cancer research, identification of therapeutic targets and the optimal use of preventative and integrated treatment interventions to achieve improved outcomes, enhanced survival and quality of life for the cancer patient.

\section{Dovepress}

View the full aims and scopes of this journal here. The manuscript management system is completely online and includes a very quick and fair peer-review system, which is all easy to use. Visit http:// www.dovepress.com/testimonials.php to read real quotes from published authors.

Submit your manuscript here: http://www.dovepress.com/breast-cancer---targets-and-therapy-journal 